\title{
A Topographical Study of Nutrient Foramen in Human Fibulae
}

\section{ABSTRACT}

Introduction: The fibula is very well known amongst the surgeons for their usage in bone grafting. The vascularised bone graft is necessary for successful procedure. The vasculature of the bone graft is maintained by procuring the intact nutrient artery along the donor site of the bone. The nutrient artery enters the shaft of the bone through the nutrient foramen. The topographical study of nutrient foramen in human fibulae will benefit the operating surgeons in the surgical procedures like open reduction fracture of the fibula and bone grafting.

Aim: To record the position, location, number and direction of the nutrient foramen of the fibula.

Materials and Methods: A descriptive study on 100 human dried fibulae obtained from the Department of Anatomy, Seth GSMC and KEM hospital, Mumbai, Maharashtra, India were done from February 2013 to July 2013. A magnifying hand lens and a thin stiff wire to confirm the number and direction of nutrient foramen were used. The lengths of the fibulae were measured and divided into three equal parts. The position and location were determined by identifying the anatomical position and the side of the fibula. The simple statistical method by calculating frequency (n) and percentages (\%) in all categories and sub-categories of the collected data was applied to the study.

Results: In $17.24 \%$ of fibulae the foramen was directed towards the growing end. In $7 \%$ of fibulae, there was no foramen, $23 \%$ fibulae were having two foramina, and $70 \%$ were having one foramen. The nutrient foramen was located maximally on the posterior surface of the fibula (84.48\%) and in the middle onethird (81.03\%).

Conclusion: This study has provided information on the topography of nutrient foramen of the fibula. This knowledge will be useful in certain surgical procedures to preserve the vascularity of fibula.

\section{INTRODUCTION}

The word "Fibula" in Latin means brooch, together with tibia. It resembles an ancient brooch or pin. The fibula though contributes insignificantly in weight distribution, is an important bone for muscle attachment and a significant source of bone graft [1]. The nutrient foramen in the long bones of human limbs is directed towards the elbow and away from the knee. This is due to, the faster growth of one end than another. The knowledge of the nutrient artery passing through the nutrient foramen is essential in procedures like bone grafts [1], tumour resection [2], traumas, transplant techniques in orthopaedics and plastic surgeries [3].

The fibula is commonly used as a free vascularised bone graft for reconstruction of mandible, spine, and even the tibia. In free vascularised bone grafting the nutrient artery should be preserved to promote fracture healing [3]. The knowledge about the location of nutrient foramen will guide us to locate the entry point of the nutrient artery into the bone, thus it will be helpful to preserve the circulation.

The complications like neurovascular injuries, compartment syndrome and ankle instability are common during fibular graft harvesting [4]. Thus, the data regarding the position of a nutrient foramen in a different population can improve the result and minimise the complication. The knowledge of number and position of the nutrient foramen is important for the orthopaedic surgeon during the open reduction of the fracture, to avoid the occurrence of injury to the nutrient artery and thereby decrease the chances of delayed or non union of the fracture [5]. Through the radiograph, the nutrient canal is visualised on the tangential view and is confined to the cortex. If the radiolucency extends beyond the cortex, a fracture should be suspected. However, an atypical nutrient canal may simulate a fracture. The cause of such an atypical appearance is the extension of the linear radiolucency beyond the confines of the cortex [6]. Thus, prior knowledge about the commonest position of nutrient foramen will help to minimise the error in diagnosis. For these reasons, it is necessary to understand the precise location and relevant anatomy of nutrient foramen. Though many authors have performed a similar study, there has been a variation in the findings due to different racial groups and regions of the study population [7-9]. Hence, the present study aimed to determine the number, direction, and position of a nutrient foramen in human fibulae and its relationship to the growing end of a bone, pretty useful information useful for the clinicians operating in the particular region.

\section{MATERIALS AND METHODS}

This was the descriptive study conducted on hundred human dried fibulae of unknown sex, obtained from the Department of Anatomy, Seth GSMC and KEM Hospital, Mumbai were studied for the period of five months from February 2013 to July 2013. Nutrient foramina were identified by the presence of a well-marked groove and the slightly raised edge at the commencement of that canal. Magnifying hand lens and thin stiff wire to determine the number and direction of nutrient foramen were used.

Inclusion criteria: All adult human fibulae available in the Department of Anatomy, irrespective of age and sex were included in the study.

Exclusion criteria: Broken bones and bones with gross pathological deformities were excluded from the study.

The side of bone was determined and the total length of bone was measured with the help of thread and metre tape. Total length was divided into three equal parts as upper $1 / 3^{\text {rd }}$, middle $1 / 3^{\text {rd }}$, and lower $1 / 3^{\text {rd }}$ [Table/Fig-1]. The number, direction, and position of nutrient foramen on the shaft of fibula were noted. The surfaces or borders of fibula were named according to the standard Anatomy textbook [10]. 

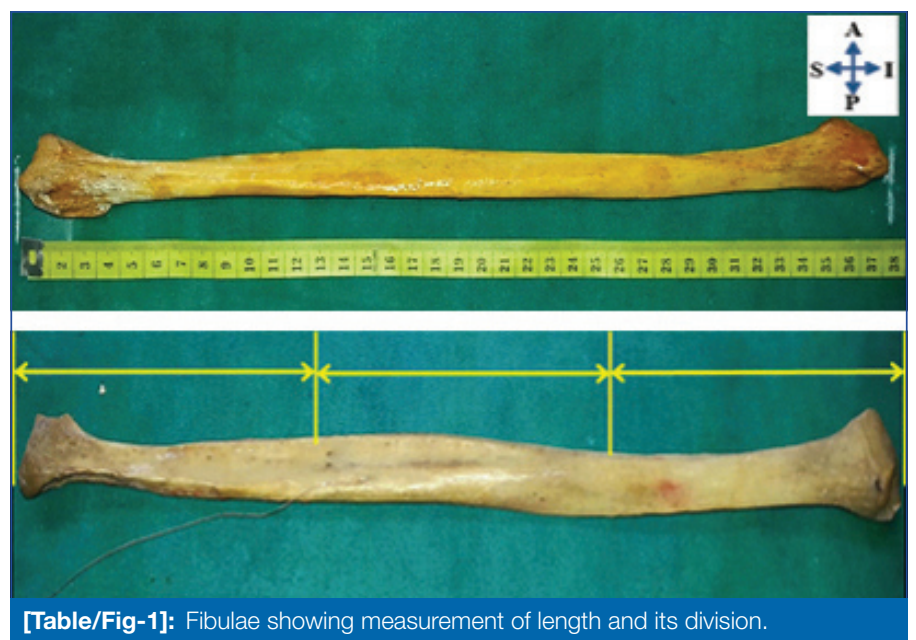

\section{STATISTICAL ANALYSIS}

Findings were tabulated and simple statistics were applied by calculating frequency $(\mathrm{n})$ and percentages $(\%)$ in all categories and sub-categories of the collected data.

\section{RESULTS}

A total sample of hundred dried fibulae of unknown sex were obtained, of which 46 were of the right side and 54 were of the left side. In the present study, $17.24 \%$ of fibulae the foramen was directed towards the growing end [Table/Fig-2]. In $7 \%$ of fibulae, there was no foramen, $23 \%$ fibulae were having two foramina [Table/ Fig-3], and 70\% were having one foramen [Table/Fig-4]. The nutrient foramen was located maximally on the posterior surface of the fibula (84.48\%) and in the middle 1/3rd (81.03\%) [Table/Fig-5-7]. In 9.4\% of fibulae the foramina were located on medial surface [Table/Fig-8].

\begin{tabular}{|c|c|c|c|c|c|}
\hline Side & $\begin{array}{l}\text { No. of } \\
\text { fibulae }\end{array}$ & $\begin{array}{l}\text { No. of nutrient } \\
\text { foramen }\end{array}$ & Direction & Number & $\%$ \\
\hline \multirow{2}{*}{ Right } & \multirow{2}{*}{46} & \multirow{2}{*}{55} & Towards the growing end & 11 & 20 \\
\hline & & & Away from the growing end & 44 & 80 \\
\hline \multirow{2}{*}{ Left } & \multirow{2}{*}{54} & \multirow{2}{*}{61} & Towards the growing end & 9 & 14.75 \\
\hline & & & Away from the growing end & 52 & 85.24 \\
\hline \multirow{2}{*}{ Total } & \multirow{2}{*}{100} & \multirow{2}{*}{116} & Towards the growing end & 20 & 17.24 \\
\hline & & & Away from the growing end & 96 & 82.76 \\
\hline
\end{tabular}

[Table/Fig-2]: Study of the direction of a nutrient foramen in 100 fibulae.
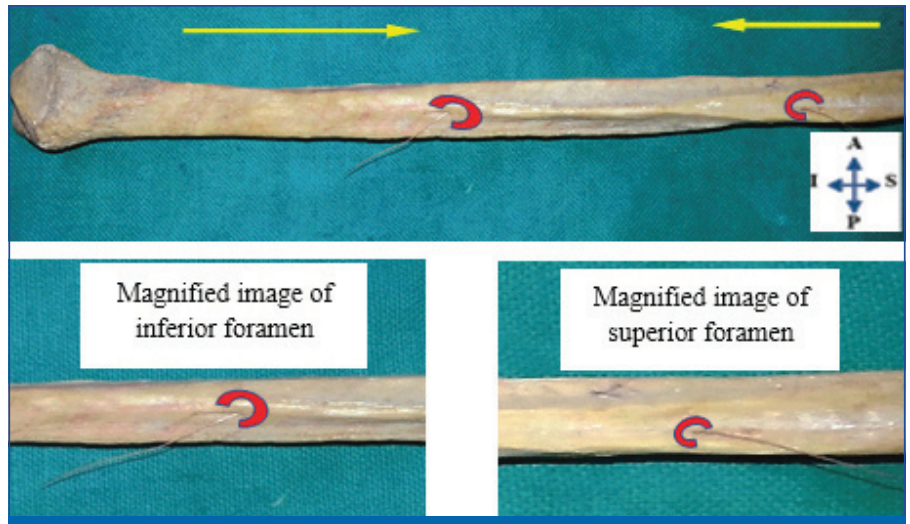

[Table/Fig-3]: Location and direction of two nutrient foramina on the posterior surface of the right fibula.

Red mark $\mathrm{C}$ denotes margin of foramen, arrow mark $(\leftarrow)$ denotes direction of foramen

\begin{tabular}{|l|c|c|c|c|c|c|}
\hline \multirow{2}{*}{$\begin{array}{l}\text { No. of } \\
\text { foramen }\end{array}$} & \multicolumn{2}{|c|}{ Right fibulae (46) } & \multicolumn{2}{c|}{ Left fibulae (54) } & \multicolumn{2}{c|}{ Total fibulae (100) } \\
\cline { 2 - 7 } & $\begin{array}{c}\text { No. of } \\
\text { fibulae }\end{array}$ & $\%$ & $\begin{array}{c}\text { No. of } \\
\text { fibulae }\end{array}$ & $\%$ & $\begin{array}{c}\text { No. of } \\
\text { fibulae }\end{array}$ & $\%$ \\
\hline 0 & 3 & 6.52 & 4 & 7.40 & 7 & 7 \\
\hline 1 & 31 & 67.39 & 39 & 72.22 & 70 & 70 \\
\hline 2 & 12 & 26.08 & 11 & 20.37 & 23 & 23 \\
\hline
\end{tabular}
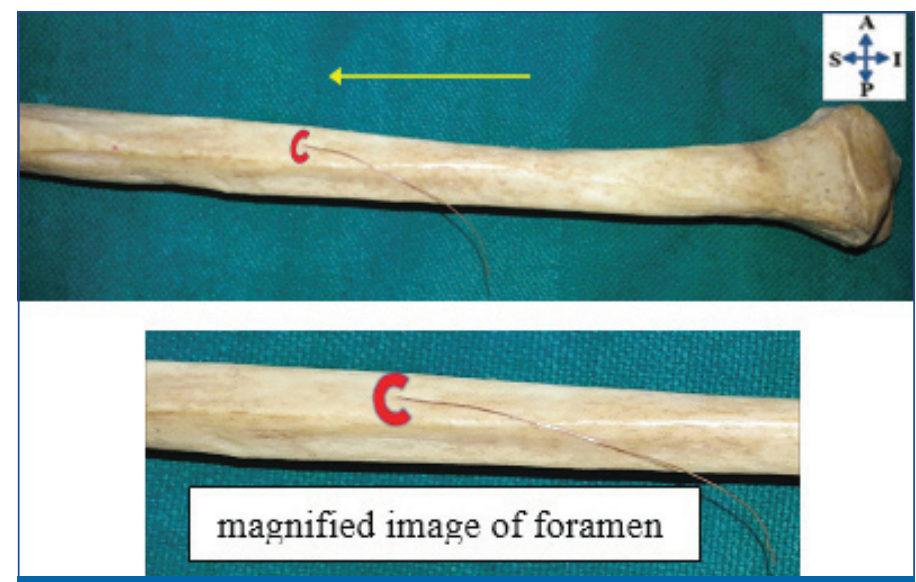

[Table/Fig-5]: Location and direction of nutrient foramen on the posterior surface of left fibula.

Red mark $\mathrm{C}$ denotes margin of foramen, arrow mark $(\leftarrow)$ denotes direction of foramen

\begin{tabular}{|c|c|c|c|c|c|}
\hline Side & $\begin{array}{l}\text { No. of } \\
\text { fibulae }\end{array}$ & $\begin{array}{l}\text { No. of nutrient } \\
\text { foramen }\end{array}$ & Lengthwise distribution & Number & $\%$ \\
\hline \multirow{3}{*}{ Right } & \multirow{3}{*}{46} & \multirow{3}{*}{55} & Upper $1 / 3^{\text {rd }}$ & 4 & 7.27 \\
\hline & & & Middle $1 / 3^{\text {rd }}$ & 44 & 80 \\
\hline & & & Lower $1 / 3^{\text {rd }}$ & 7 & 12.72 \\
\hline \multirow{3}{*}{ Left } & \multirow{3}{*}{54} & \multirow{3}{*}{61} & Upper $1 / 3^{\text {rd }}$ & 3 & 4.91 \\
\hline & & & Middle $1 / 3^{\text {rd }}$ & 50 & 81.96 \\
\hline & & & Lower $1 / 3^{\text {rd }}$ & 8 & 13.11 \\
\hline \multirow{3}{*}{ Total } & \multirow{3}{*}{100} & \multirow{3}{*}{116} & Upper $1 / 3^{\text {dd }}$ & 7 & 6.03 \\
\hline & & & Middle $1 / 3^{\text {rd }}$ & 94 & 81.03 \\
\hline & & & Lower $1 / 3^{\text {rd }}$ & 15 & 12.93 \\
\hline
\end{tabular}

[Table/Fig-6]: Distribution of nutrient foramen on the shaft of 100 fibulae.

\begin{tabular}{|c|c|c|c|c|c|}
\hline Side & $\begin{array}{l}\text { No. of } \\
\text { fibulae }\end{array}$ & $\begin{array}{l}\text { No. of nutrient } \\
\text { foramen }\end{array}$ & Surface & Number & $\%$ \\
\hline \multirow{3}{*}{ Right } & \multirow{3}{*}{46} & \multirow{3}{*}{55} & Medial & 6 & 10.90 \\
\hline & & & Lateral & 4 & 7.27 \\
\hline & & & Posterior & 45 & 81.81 \\
\hline \multirow{3}{*}{ Left } & \multirow{3}{*}{54} & \multirow{3}{*}{61} & Medial & 5 & 8.91 \\
\hline & & & Lateral & 3 & 4.91 \\
\hline & & & Posterior & 53 & 86.88 \\
\hline \multirow{3}{*}{ Total } & \multirow{3}{*}{100} & \multirow{3}{*}{116} & Medial & 11 & 9.4 \\
\hline & & & Lateral & 7 & 6.03 \\
\hline & & & Posterior & 98 & 84.48 \\
\hline
\end{tabular}

[Table/Fig-7]: Location of nutrient foramen on the various surface of the shaft of 100 fibulae.
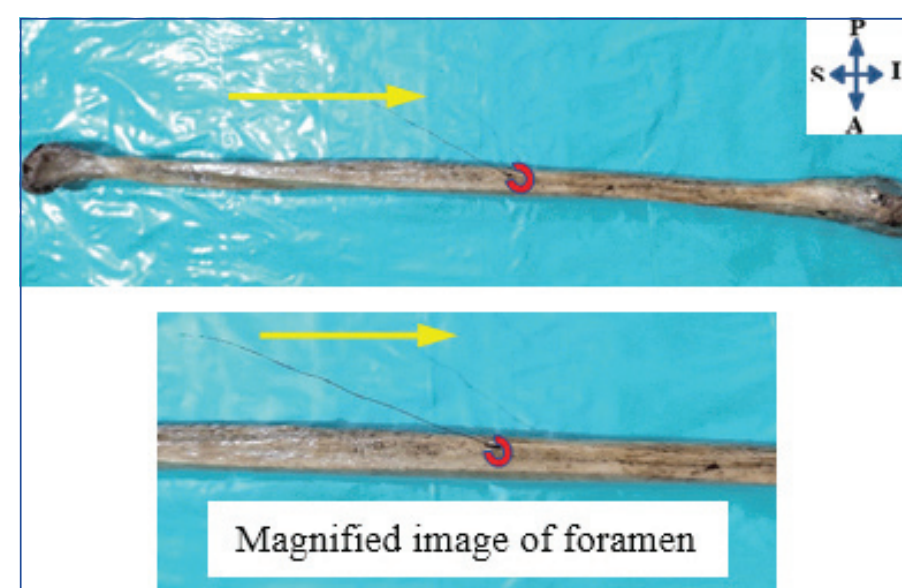

[Table/Fig-8]: Location and the direction of the nutrient foramen on the medial surface of the right fibula.

Red mark $\mathrm{C}$ denotes margin of foramen, arrow mark $(\leftarrow)$ denotes direction of foramen

\section{DISCUSSION}

The number of nutrient foramina: In the present study, $70 \%$ of fibulae had single foramen, $23 \%$ had two, and $7 \%$ had no foramen. 
Mysorekar VR found one foramen in 92.8\% fibulae, two foramina in $3.3 \%$, and $3.9 \%$ fibulae showed no foramen [11]. McKee NH et al., studied 323 fibulae, out of this only $0.3 \%$ had three foramina while $86.4 \%$ had one foramen, $7.7 \%$ had two, $6 \%$ had no foramen [7]. Forriol CF et al., studied 33 fibulae and $100 \%$ of fibulae in his study had single foramen [8]. All comparative data is tabulated in [Table/Fig-9] [7-9,11-14].

\begin{tabular}{|l|c|c|c|c|c|}
\hline & \multirow{2}{*}{ No. of } & \multicolumn{4}{|c|}{ No. of foramen } \\
\cline { 4 - 7 } futhors & 180 & $3.9 \%$ & $92.8 \%$ & $3.3 \%$ & 0 \\
\hline Mysorekar VR (1967) [11] & 100 & $4 \%$ & $94 \%$ & $2 \%$ & 0 \\
\hline Restrepo J et al., (1980) [12] & 295 & $1.7 \%$ & $94.9 \%$ & $3.4 \%$ & 0 \\
\hline Fen G (1981) [13] & 323 & $5.6 \%$ & $86.4 \%$ & $7.7 \%$ & $0.3 \%$ \\
\hline McKee NH et al., (1984) [7] & 33 & $0 \%$ & $100 \%$ & $0 \%$ & 0 \\
\hline Forriol CF et al., (1987) [8] & 69 & $18.8 \%$ & $73.9 \%$ & $7.2 \%$ & 0 \\
\hline Sendemir E and Cimen A (1991) [14] & 60 & $3.3 \%$ & $85 \%$ & $11.7 \%$ & 0 \\
\hline Gumusburun E et al., (1994) [9] & 100 & $7 \%$ & $70 \%$ & $23 \%$ & 0 \\
\hline Present study (2021) & & $7 \%$ & 3 \\
\hline [Table/Fig-9]: Comparison on the basis of number of Nutrient foramina [7-9,11-14].
\end{tabular}

Mysorekar VR in his study stated that there is no relationship between more number of foramen and the length of the bone [11]. But in case of total absence of nutrient foramen, the bones were usually supplied by periosteal arteries [15]. While selecting the level of an osseous section in the recipient in transplant surgery to place the graft without damaging the nutrient arteries, the thorough knowledge of the statistical distribution of nutrient foramina on long bones is necessary [16]. Thus, this knowledge of the position and number of the nutrient foramina in fibula is important for the orthopaedic surgeons to perform bone grafts and vascularised bone microsurgery.

Distribution of nutrient foramen on the shaft: A maximum number of nutrient foramina were located in the middle third of the shaft (81.03\%) according to the present study and those studies were done by Mckee NH et al., (96\%) and Gumusburun E et al., (92.3\%) $[7,9]$. Guo F reported that the distribution of the number of foramina was maximum in the upper third of the shaft (66.4\%) [Table/Fig-10] $[7,9,17]$. It is important to preserve the nutrient blood supply of the free vascularised bone graft, so that osteoblasts and the osteocytes in the graft may survive, and thus graft healing is facilitated by creeping substitution [9]. The knowledge about the variations in the distribution of the nutrient foramina of the fibula is important as it is frequently used in bone grafting. Analysing the present study, the segment of choice for performing graft is the middle third of the shaft of fibula if one desires sufficient vascularisation of the graft.

\begin{tabular}{|c|c|c|c|}
\hline Authors & \multicolumn{3}{|c|}{ Distribution } \\
\hline Gumusburun E et al., [9] & \multicolumn{3}{|c|}{ Maximum distribution in middle $1 / 3^{\text {rd }}(92.3 \%)$} \\
\hline McKee NH et al., [7] & \multicolumn{3}{|c|}{ Maximum distribution in middle $1 / 3^{\text {rd }}(96 \%)$} \\
\hline Guo F [17] & \multicolumn{3}{|c|}{ Maximum distribution in upper $1 / 3^{\text {rd }}(66.4 \%)$} \\
\hline \multirow{2}{*}{ Present study } & Upper $1 / 3^{\text {rd }}$ & Middle $1 / 3^{\text {rd }}$ & Lower $1 / 3^{\text {rd }}$ \\
\hline & $6.03 \%$ & $81.03 \%$ & $12.93 \%$ \\
\hline
\end{tabular}

Adequate dissection around the position and the location of the nutrient foramen will minimise the length of the incision in harvesting the vascularised graft of fibula. This will decrease the complication of the procedure such as compartment syndrome.

Location of nutrient foramen: The present study shows that most of the nutrient foramen was located on the posterior surface of the bone (84.48\%). Kizilkanat $\mathrm{K}$ et al., stated that the position of the nutrient foramina was dependent on the requirement of the blood supply to the particular aspect of the bone, commonly in the region with more muscle attachments [18]. Being bulkier, and stronger, the flexor muscles need more blood supply than the extensors of the limb.
The foramen is a potential site of weakness and due to stress-induced by excess physical activity is prone to fracture. The knowledge of the position of the nutrient foramen is important in the diagnosis of such longitudinal stress fracture, as they frequently initiate from the nutrient foramen as depicted in study by Craig JG et al., [19].

The vascular integrity of long bones is vital hence tracing the correct location of nutrient foramen may be of value for the orthopaedic surgeons. Periosteal stripping and exposure of bone is done in open reduction and internal fixation procedure, which hampers the existing vascularity of bone. Hence, depending upon the site of fixation, proper exposure of the bony surface is done avoiding injury to the nutrient artery as observed in study by Nagel A [5].

A maximum number of foramina which were noted in the studies proposed by Gumusburun E et al., (88.5\%) and Mysorekar VR (56\%), were on the medial surface $[9,11]$. The studies by Mckee $\mathrm{NH}$ et.al., (67.5\%) and Forriol CF et al., (50\%) however showed similarities with the findings of the present study [Table/Fig-11] [7,8]. These differences in the findings regarding positions of foramen were probably due to the bulkier and stronger muscle in the specific surface of the bone.

\begin{tabular}{|l|c|c|c|}
\hline \multirow{2}{*}{ Authors } & \multicolumn{3}{|c|}{ Location } \\
\cline { 2 - 4 } & Medial & Lateral & Posterior \\
\hline Gumusburun E et al., [9] & $88.5 \%$ & $1.6 \%$ & $9.8 \%$ \\
\hline Mysorekar VR [11] & $56 \%$ & $18 \%$ & $26 \%$ \\
\hline Forriol CF et al., [8] & $50 \%$ & - & $50 \%$ \\
\hline McKee NH et al., [7] & $13 \%$ & $19.5 \%$ & $67.5 \%$ \\
\hline Present study & $9.4 \%$ & $6.03 \%$ & $84.48 \%$ \\
\hline [Table/Fig-11]: Comparison on the basis of location of Nutrient foramen [7-9,11].
\end{tabular}

The direction of nutrient foramen: Numerous theories have been proposed to explain the direction of the canals, and also the anomalously directed ones. These include the 'periosteal slip' theory of the vascular theory and the muscular theory [20].

Schwalbe $G$ explained that before birth, the nutrient foramen is horizontally oriented because two ends of bone grow equally before appearance of the epiphysis [21]. When the epiphysis develops, the growing end determines the direction of the nutrient foramen, as the one end grows faster than the other end. But this theory fails to explain the abnormal direction of foramina. Additional information provided by the theory of periosteal slip is that the foramina which are in the periphery of shaft are more oblique than at the centre. This is because the nutrient artery which enters foetal long bone at the middle of the shaft will be perpendicular than the artery which enters the shaft at the epiphyseal end will attain more obliquity [20]. Lacroix $P$ suggested that asymmetrical muscular development can produce traction force on periosteum to cause even reversal of direction of entry of nutrient artery into diaphysis [22]. Hughes $\mathrm{H}$ suggested that the growth of artery occurs by equal increments in its unit length hence the unequal growth of two epiphyses will cause the artery to direct towards the opposite side of quicker growth [23]. The present study showed $82.76 \%$ of nutrient foramen was directed away from the growing end. The anomalous direction of nutrient foramen was probably justified by the above-explained theory.

\section{Limitation(s)}

As this study was done in the dry bone, the results cannot be directly correlated with the living individuals. The bones used in this study were gathered from bone museum which were stored for many years, may slightly differs the anatomy. The age and sex differences are not studied, knowing these differences might have altered the result as the anatomy is different in these groups. As the bones are randomly collected from the museum, the gender differentiation could not be done. 


\section{CONCLUSION(S)}

This study has provided information on the topography of nutrient foramen of the fibula. This knowledge will be useful in certain surgical procedures to preserve the vascularity of fibula. Appropriate dissection around nutrient foramen for fibular graft will minimise the chances of rejection of graft and allow harvesting of the graft with a minimum incision. This study has opened an avenue for further research in this area through the radiological approach.

\section{Acknowledgement}

The author would like to acknowledge the support rendered by Dr. P.S. Bhuiyan, Professor and Head of Department of Anatomy, Dr. Lakshmi Rajgopal, Additional Professor of Department of Anatomy, Seth G.S. Medical College and K.E.M Hospital Mumbai and Dean Seth G.S. Medical College and K.E.M Hospital Mumbai for carrying out this study.

\section{REFERENCES}

[1] Bae DS, Waters PM. Free vascularised fibula grafting: Principles, techniques, and applications in pediatric orthopaedics. Orthopaedic Journal at Harvard Medical School. 2006;8:86-89.

[2] Yuan SM, Cui L, Guo Y, Wang J, Hu XB, Jiang HQ, et al. Surgical management of giant neurofibroma in soft tissue: A single-centre retrospective analysis. Int $J$ Clin Exp Med. 2015;8(4):5245-53.

[3] Sherbiny ML, Shrief AMR. New technique of reconstruction after resection of tumors of the distal femur: Role of inverted pedicled fibular graft. Journal of the Egyptian Nat. Cancer Inst. 2003;15(3):235-42.

[4] Maraskolhe DS, Bhalotia AP, Jaiswal P. Complications of fibular bone grafting at the donor site. International Journal of Orthopaedics Sciences. 2018;4(2):482-84.

[5] Nagel A. The clinical significance of the nutrient artery. Orthop Rev. 1993;22(5):557-61.
[6] Lee JH, Ehara S, Tamakawa Y, Horiguchi M. Nutrient canal of the fibula. Skeletal Radiol. 2000;29(1):22-26.

[7] McKee NH, Haw P, Vettese T. Anatomic study of the nutrient foramen in the shaft of the fibula. Clin Orthop Relat Res. 1984;184:141-44. PMID: 6705337.

[8] Forriol CF, Pellico LG, Alias MG, Valencia R. A study of the nutrient foramina in human long bones. Surg Radiol Anat. 1987;9(3):251-55.

[9] Gumusburun E, Yucel F, Ozkan Y, Akgun Z. A study of the nutrient foramina of lower limb long bones. Surg Radiol Anat. 1994;16(4):409-12.

[10] Standring S, Neel A, Rolfe B, Collins P, Crossman A, Gleeson M, et al. Leg. In: Robert J Spinner, Benjamin M Howe. Gray's anatomy: The anatomical basis of clinical practice. $41^{\text {st }}$ ed. Edinburgh: Elsevier; 2016. Pp.1405.

[11] Mysorekar VR. Diaphysial nutrient foramina in human long bones. J Anat. 1967;101(4):813-22.

[12] Restrepo J, Katz D, Gilbert A. Arterial vascularisation of the proximal epiphysis and the diaphysis of the fibula. Int J Microsurg. 1980;2:49-54.

[13] Fen G. Fibular blood supply. Chin Med J. 1981;94(6):396-400

[14] Sendemir E, Cimen A. Nutrient foramina in the shafts of lower limb long bones: Situation and number. Surg Radiol Anat.1991;13(2):105-08.

[15] Patake SM, Mysorekar VR. Diaphysial nutrient foramina in human metacarpals and metatarsals. J Anat. 1977;124(Pt 2):299-304.

[16] Kirschner MH, Menck J, Hennerbichler A, Gaber O, Hofmann GO. Importance of arterial blood supply to the femur and tibia for transplantation of vascularised femoral diaphyses and knee joints. World J Surg. 1998;22(8):845-52.

[17] Guo F. Observations of the blood supply to the fibula. Arch Orthop Traumat Surg. 1981;98(2):147-51.

[18] Kizilkanat E, Boyan N, Ozsahin ET, Soames R, Oguz O. Location, number, and clinical significance of nutrient foramina in human long bones. Ann Anat. 2007;189(1):87-95.

[19] Craig JG, Widman D, Van HM. Longitudinal stress fracture: Patterns of edema and the importance of nutrient foramen. Skeletal Radiol. 2003;32(1):22-27.

[20] Shulman SS. Observations on the nutrient foramina of the human radius and ulna. Anat Rec.1959;134:685-97. Doi: 10.1002/ar.1091340404.

[21] Schwalbe G. Zeitschrift fur Anatomie und Entwicklungsgeschichte. 1876;1:307-52.

[22] Lacroix P. The organization of bones. London: J \& A Churchill, 1951.

23] Hughes $\mathrm{H}$. The factors determining the direction of the canal for the nutrient artery in the long bones of mammals and birds. Acta Anat (Basel). 1952;15(3):261-80.

PARTICULARS OF CONTRIBUTORS:

1. Associate Professor, Department of Anatomy, BKL Walawalkar Rural Medical College, Sawarde, Maharashtra, India.

NAME, ADDRESS, E-MAIL ID OF THE CORRESPONDING AUTHOR:

Prashant Mohan Moolya,

217/1/2, Sumohan Nivas, Behind Janata Hotel, Budhwarpeth, Madhavnagar,

Sangli, Maharashtra, India.

E-mail: prashantmmoolya@gmail.com

\section{AUTHOR DECLARATION:}

- Financial or Other Competing Interests: None

- Was Ethics Committee Approval obtained for this study? No

- Was informed consent obtained from the subjects involved in the study? No

- For any images presented appropriate consent has been obtained from the subjects. No
PLAGIARISM CHECKING METHODS: Jain Het al.]

- Plagiarism X-checker: Apr 23, 2021

- Manual Googling: Aug 16, 2021

- iThenticate Software: Sep 06, 2021 (20\%)
ETYMOLOGY: Author Origin

Date of Submission: Apr 23, 2021

Date of Peer Review: Jun 08, 2021

Date of Acceptance: Aug 17, 2021

Date of Publishing: Oct 01, 2021 